\title{
Comparative Study between Negative Pressure Wound Therapy and Platelet Rich Plasma in Neovascularization of Chronic Wound Healing
}

\author{
AHMED G. EL-NAGAR, M.Sc.*; AHMED A.M. KHALIL, M.D.**; AMIRA K. EL-HAWARY, M.D.***; \\ SAMY A. SHEHABELDIN, M.D.** and AHMED M. BAHAA, M.D.** \\ The Department of Plastic Surgery, Ahmed Maher Teaching Hospital*, The Departments of Plastic Surgery** and Pathology***, \\ Faculty of Medicine, Mansoura University
}

\begin{abstract}
Background: Chronic wound healing is a significant health problem. Increased angiogenesis and blood flow had been shown to facilitate the healing of chronic wounds. Negative pressure wound therapy and platelet rich plasma may be used for treatment of various chronic wounds, especially when standard conventional therapy is not good enough or for preparation for definitive closure.
\end{abstract}

Objectives: To compare the efficacy of negative pressure wound therapy and platelet rich plasma in neovascularization of chronic wound healing.

Patient and Method: Twenty patients with chronic wound were divided into two groups. Wound tissue biopsies were collected from the centeraland peripheral of the wound before starting our procedure and after one, two and three weeks in both groups. Evaluation of the wound clinically and Immunohistochemically for vascular endothelial growth factor (VEGF) and CD31 (cluster of differentiation) were done.

Results: PRP and NPWT were effective in neovasculization and stimulation of healing process. The expression of VEGF in PRP patients after the third week was mild $10 \%$, moderate $20 \%$, strong $70 \%$ and was mild $10 \%$, moderate $20 \%$, strong $70 \%$ in peripheral and central tissue biopsy respectively. While in NPWT patient was mild $20 \%$, moderate $30 \%$, strong $50 \%$ in both peripheral and central tissue biopsy. The average of blood vessels formation in CD-31 was 9.95 \pm 3.64 after 3 week in peripheral tissue biopsy and was $8.58 \pm 3.51$ in central tissue biopsy in PRP patients. While in NPWT patients was $8.35 \pm 3.25$ in peripheraltissue biopsy and was $8.38 \pm 3.12$ in central tissue biopsy.

Conclusion: PRP and NPWT are effective in treatment chronic wounds. PRP is more simple, less costly, shorter time for the method, less painful, no hospital stay and less transmission of infections.

Key Words: Wound - Platelet rich plasma - Healing.

\section{INTRODUCTION}

Chronic wound healing is a major health problem, mainly in older adults. Beside to the suffering, pain and failure of the healing process also had financial and social burdens [1].
It is recognized that effective wound management requires a comprehensive assessment of both the patient and the wound to determine the optimal treatment plan for achieving wound care goals. Numerous wound and patient risk factors are known to potentially complicate wound healing and increase health care costs [2].

Conventional treatments include debridement and dressing like gauze, sofra tulle, films, foam, and hydrogel but, in many cases, these treatments do not result in reliably satisfactory outcomes [3]. Consequently, there had been heightened interest in developing new advanced therapies to address the compromised wound. Specifically, in the treatment of chronic wounds, platelet-rich plasma (PRP) and negative pressure wound therapy (NPWT) shown promising experimental and clinical results [4].

A variety of growth factors, cytokines, and lipid mediators produced in response to injury can stimulate angiogenesis. One of the most important proangiogenic mediators is vascular endothelial growth factor (VEGF), and sufficient VEGF levels are believed to be essential for proper wound healing [5].

VEGF stimulates angiogenesis, wound closure, epidermal repair, granulation tissue formation, and the quality of repair include the strength of the healed wound and the amount of scar tissue, most of the effects of VEGF during wound repair had been attributed to its proangiogenic activity [6].

\section{Negative pressure wound therapy:}

Modern negative pressure wound therapy (NPWT) was introduced in the 1990s for treatment of non-healing wounds [7]. 
NPWT stimulate the healing process through changing in perfusion by increased and decreased blood flow leading to local increase in a number of angiogenesis-related growth factors. This cycling of hypo and hyper perfusion of the wound stimulates angiogenesis and delivers nutrients, decrease bacterial load enhancing wound healing [8].

\section{Platelet rich plasma:}

Autologous PRP is a platelet suspension in plasma derived from whole blood that is increasingly being used in clinical practice for the treatment of chronic wound [9].

The curative properties of PRP rely on the fact that platelets are a physiological reservoir of a variety of growth factors, with healing function which had an active role in tissue regeneration [10].

Platelet granules contains large number of growth factors, which have the ability of synthesis de novo protein, and its antimicrobial activity and inflammation modulator promote proliferation of cell and extracellular matrix synthesis promoting wound healing [11].

\section{PATIENTS AND METHODS}

In this study we compared the efficacy of negative pressure wound therapy and platelet rich plasma in neovascularization of chronic wound healing.

In the current study twenty patients were included with a history of chronic wound that not heal for three weeks or more. This study was conducted at the Plastic, Reconstructive and Burn Surgical Center, the Pathology Department Mansoura Faculty of Medicine and Plastic, Reconstructive and Burn Surgical Department Ahmed Maher Teaching Hospital from January 2013 to January 2017.

\section{Inclusion criteria:}

Adult patients aging from 16-55 years with a history of chronic wound that not healed for three weeks or more with inflammatory origin. Despite treatment of the underlying causes and appropriate local wound management.

\section{Exclusion criteria:}

Patients with chronic renal or hepatic impairment, sinus of unknown depth or origin, wound with malignancy, unstable fractures, untreated osteomyelitis, and wounds with open joints, wounds with exposed blood vessels or organs, thrombocytopenia, hemodynamic instability, systemic use of corticosteroids.
The twenty patients of the study were subdivided equally into two groups:

- The first group Involves 10 patients with chronic wound will be treated by platelet rich plasma.

- The second group Involves 10 patients with chronic wound were treated by negative pressure wound therapy.

Methods:.

1- Preparation of the patient:

All cases had the following steps:

(a) Historytaken. (b) Physical examination. (c) Explanation of the procedure to the patients. (d) Baseline investigations including complete blood count, liver, kidney functions, coagulation profile, HIV, Hepatitis markers. (e) HGB $>10 \mathrm{~g} / \mathrm{dl}$. (f) Platelet count $>105 / \mathrm{ul}$. (g) Informed consent was taken.

\section{2- Preparation of the wound:}

The following steps had been followed:

(a) Wound swab for culture and sensitivity for exclusion any resistant infections. (b) Biopsy for assessment the type of the wound and exclude malignancy. (c) Debridement of the wound if needed. (d) Washing the wound with normal saline. (e) Baseline photography and before every dressing change was taken. (f) Infiltration of local anesthesia lidocaine $2 \%$ at the centreand periphery of the wound was done. (g) Punch biopsy $3 \mathrm{ml}$ taken from the center and peripheral of the wound for immunohistochemically evaluation.

\section{Preparation of platelet rich plasma:}

Twenty $\mathrm{ml}$ venous whole blood was obtained by veni-puncture divided into 6 sodium citrate tubes centrifuged by using a desktop centrifugation system (800D centrifuge). First centrifugation the blood using a 'soft' spin (250g for 10 minutes) was done. The super natant plasma containing platelets was transferred into another sterile tube (without anticoagulant) by using sterile pipette. Second centrifugation at a higher speed a hard spin (1000g for 10 minutes) was done to obtain a platelet concentrate [12].

The lower half was platelet rich plasma (PRP) and upper half was platelet poor plasma (PPP). PPP was removed and PRP was put in one cc syringe. Injection of half amount of PRP in the wound at the level of subcutaneous and the other half was put on the surface of the wound as a dressing. The wounds were covered by first layer of sterilized gauze and secondary absorbent layer were used to cover the wounds. PRP dressing done twice weekly. 


\section{Application of NPWT:}

Hands were washed and dried. For reduction of odor and maintaining the viability of the skin, the wound and peri wound area were cleansed at each dressing change. Sterile open pore foam dressing designed for placed in the wound. The size of the foam was designed to be a slightly smaller than the actual wound size. The number of pieces should be recorded if more than one piece of foam was used in the wound bed. The clear plastic sterile seal (opsite) was applied to cover all of the foam. The sterile suction tubing was passed through the hole that was made in the transparent drape covering the foam. The collection canister was connected to the sterile suction tube via the negative pressure suction device, with no contact to wound bed. Continous suction pressure on $-125 \mathrm{mmHg}$ for 48 hours then intermittent suction pressure was used with a cycle of four minutes on $-125 \mathrm{mmHg}$ and two minutes $-75 \mathrm{mmHg}$. Daily monitoring of the canisters for the type and quantity of the exudates was done. It was suggested that canisters were changed when full (an alarm will sound) and at least once a week to control odor. Dressings were changed 2 times per week, based on individual assessment. The therapy was not switched off for longer than 30 minutes and a maximum of 4 times in each 24-hour period.The dressing was to be removed and the therapy discontinued if a seal couldn't be achieved and maintained [13].

\section{Monitoring of the wound:}

\section{A- Clinically:}

The wounds were evaluated by rate of healing progress in relation to original size and suitability for skin graft application.

\section{B- Immunohistochemically:}

Wound tissue biopsies were collected from the centeral and peripheral of the wound before starting our procedure and after one, two and three weeks in both groups. The stained slides had been evaluated for vascular endothelial growth factor (VEGF) expression by cytoplasmic staining of inflammatory and endothelial cells and CD31 expression for number of blood vessels formation.

\section{RESULTS}

\section{Demographic characteristics:}

1- Age: Was ranged from 16 to 55 years with a mean of $30.6 \pm 11.7$ years and $37.5 \pm 11.9$ years in PRP patients and NPWT patients, respectively.
2- Gender: In PRP patients was $90 \%$ males (9 patients) \& $10 \%$ female (1patient). While in NPWT patients was $80 \%$ males ( 8 patients) \& $20 \%$ females ( 2 patients).

3- Special habits: $70 \%$ were non smokers (7 patients) in PRP patients \& $30 \%$ were smokers (3 patients). $60 \%$ of were non smokers (6 patient) $\& 40 \%$ were smokers (4 patients) in NPWT patients. The two studied groups had shown no difference regarding age, gender and special habits (Table 1).

\section{Clinical data of wound character:}

1- Course: Was included 30\% fluctuating (3 patients), $50 \%$ stationary (5 patients), $10 \%$ progressive (1 patient) \& $10 \%$ regressive (1 patient) in PRP patients. While in NPWT patients was $40 \%$ fluctuating (4 patients), $50 \%$ stationary ( 5 patients) \& $10 \%$ regressive (1 patient).

2- Site of wound: Was 30\% in left leg (3 patients), $40 \%$ right leg (4 patients) \& $30 \%$ right foot (3 patients) in first group. While in second group was $60 \%$ in left leg (6 patients), $10 \%$ right leg (1 patient), and $20 \%$ right foot (2 patients) \& $10 \%$ (1 patient) left thigh.

3- Size of wound: In first group was ranged from 4 to $15 \mathrm{~cm}^{2}$ with a mean of $11.0 \pm 3.3$. While in second was ranged from 10 to $15 \mathrm{~cm}^{2}$ with a mean of $12.7 \pm 1.64$.

4- Type of wound: Was $20 \%$ post burn (2 patient), $70 \%$ traumatic ( 7 patients) \& $10 \%$ venous $(1$ patient) with predominance of traumatic type in both groups.

5- Floor of the wound: Had shown 50\% unhealthy floor (5 patients) \& 50\% healthy floor of wounds (5 patients) in PRP patients. While NPWT patients was $40 \%$ unhealthy floor (4 patients) \& $60 \%$ healthy floor of wounds (6 patients).

6- Discharge: In both groups had shown fifty percent discharge with the same percentage no discharge from the wound.

7- Draining lymph node: Was 50\% (5 patients) non palpable \& $50 \%$ (5 patients) palpable in first group. The second group had shown $60 \%$ (6 patients) non palpable \& 40\% (4 patients) palpable draining lymph nodes of the wounds. There were no differences between the two studied groups regarding clinical data of wound character (Table 2).

\section{Previous treatment:}

In first group 3 patients treated with skin graft, 1 patient treated with V-Y flap \& 6 patients) had 
no history of previous treatment. In second group 4 patients treated with skin graft \& 6 patients with no history of previous treatment of the wounds. Regarding to previous treatment of the wounds no statistically difference (Table 3 ).

Surgical debridement before the procedure: 6 patients in first group had made surgical debridement \& 4 patients had not made. While 7 patients in second group had made \& 3 patients had not made surgical debridement. The $p=1.000$.

Immunohistochemically evaluation:

\section{1- VEGF expression:}

A- Peripheral wound biopsy: There were significant increased in VEGF expression in the periphery of the treated wounds in patients were treated by PRP and NPWT compared between before the application, after first, second and third weeks $(p=0.006)$ and $(p=0.009)$ respectively. But There were no differences in VEGF expressionin the tissue biopsy had been taken from the treated wounds compared between before the application, after first, second and third weeks in the patients were treated by PRP and the patients were treated by NPWT $(p=0.696)$.

B- Central wound biopsy: There were significant increased in VEGF expression in patients were treated by PRP and NPWTcompared between before the application, after first, second and third weeks $(p=0.010)$ and $(p=0.043)$ correspondingly. There were no significant differences in VEGF expression in tissue biopsy had been taken from the center of the treated wounds compared between before the application, after first, second and third weeks in the patients were treated by PRP and the patients were treated by NPWT $(p=0.696)$ (Table 4).

\section{2- CD31 Expression:}

A- Peripheral wound biopsy: There were significant increased in the number of vessels in patients were treated by PRP and NPWT compared between before the application, after first, second and third weeks in PRP was (Min-Max=4.5014.25), (Mean $\pm \mathrm{SD}=9.95 \pm 3.64)$ and a median 11.13 and was (Min-Max=4.25-12.25), (Mean $\pm \mathrm{SD}=$ $8.35 \pm 3.25$ ) and a median 8.0 in NPWT cases. There were no significant differences in the number of blood vessels in the tissue biopsy had been taken from the periphery of the treated wounds compared between before the application, after first, second and third weeks in the patients were treated by
PRP and the patients were treated by NPWT $(p=0.364)$.

B- Central wound biopsy: Therewere significant increased in the numbers of vessels in patients were treated by PRP and NPWT compared between before the application, after first, second and third weeks (Min-Max = 3.0-12.75), $($ Mean \pm SD $=$ 8.58 \pm 3.51 ) and a median 9.50. (Min-Max $=4.75$ $12.75)$, (Mean $\pm \mathrm{SD}=8.38 \pm 3.12)$ in a respective manner. There were no significant differences in the number of blood vessels in the tissue biopsy had been taken from the centers of the treated wounds compared between before the application, after first, second and third weeks in the patients were treated by PRP and the patients were treated by NPWT $(p=0.970)$ (Table 5).

Pain Scale: In the first group was grade 3 (7 patients) \& grade 2 (3 patients) with a mean of $2.7 \pm 0.5$ grade. While in second group was grade 3 (7 patients) \& grade 4 (3 patients) with a mean of $3.3 \pm 0.5$ grade. There was statistically a significant difference between the two studied groups regarding pain scale $(p=0.017)$ (Table 6).

\section{Clinical outcome:}

- Percentage of improvement at the end of setting: It was ranged from $15 \%$ to $100 \%$ with a mean $59.0 \pm 26.01 \%$ and median $62.50 \%$ in first group. While it was ranged from $10 \%$ to $100 \%$ with a mean $49.0 \pm 31.69 \%$ and median $52.50 \%$ in second group with no differences between the two groups regarding $(p=0.495)$.

- Surgical interventions: In PRP patients had been shown no surgical intervention in 9 patients and skin graft had been done in one patient. In NPWT patients had been shown no surgical intervention one patient and 9 patients had surgical intervention in the form of skin graft. The two groups had statistically difference $(p<0.001)$.

- Healing process: The first group was shown complete healing in 8 patients by secondary intension 7 patients, skin graft one patient and no healing 2 patients. In second group the patients was shown complete healing 7 patient by secondary intension one patient, skin graft 6 patient and no healing 3 patients. With a significantdifference $(p=0.040)$.

- Time of compete healing after the procedure: Was ranged from 2.0 to 7.0 weeks with a mean $4.88 \pm 1.73$ week in first group. Was ranged from 2.0 to 10.0 weeks with a mean $4.38 \pm 2.56$ week in second group. $(p=0.312)$ (Table 7). 

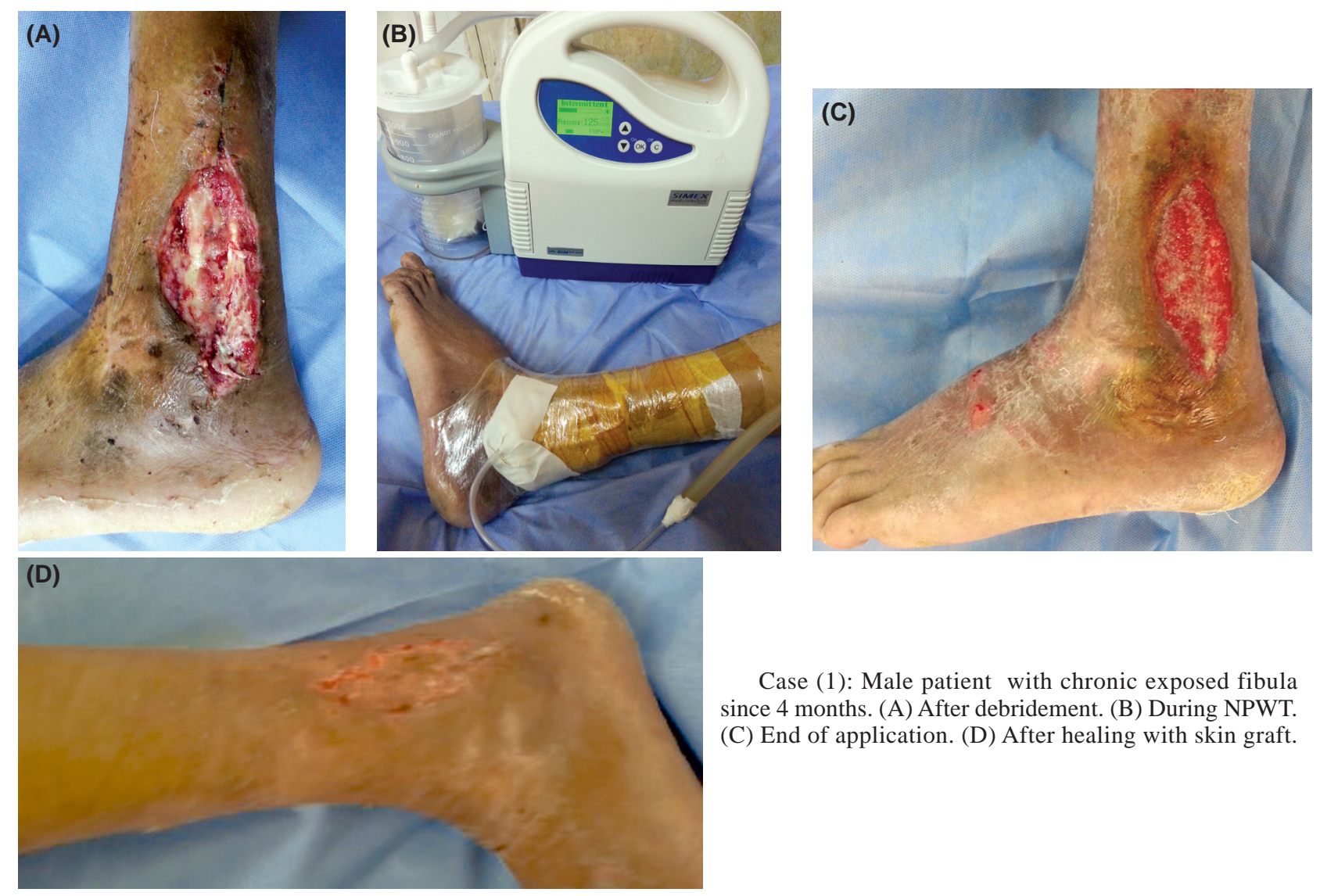

Case (1): Male patient with chronic exposed fibula since 4 months. (A) After debridement. (B) During NPWT. (C) End of application. (D) After healing with skin graft.

(A)

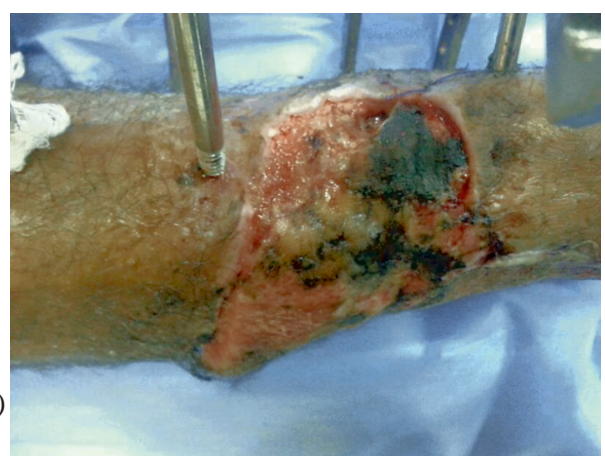

(C)

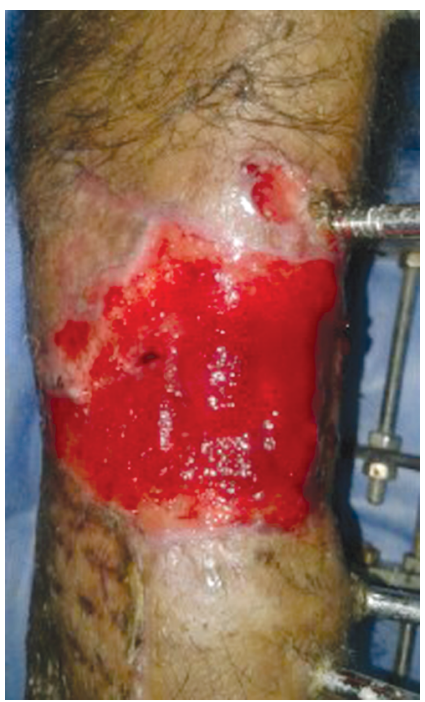

(B)

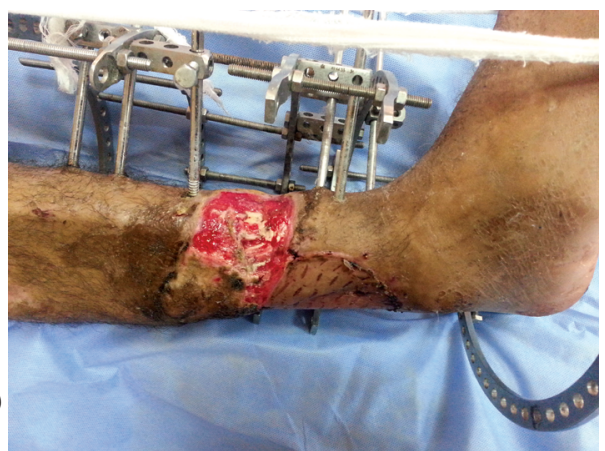

(D)

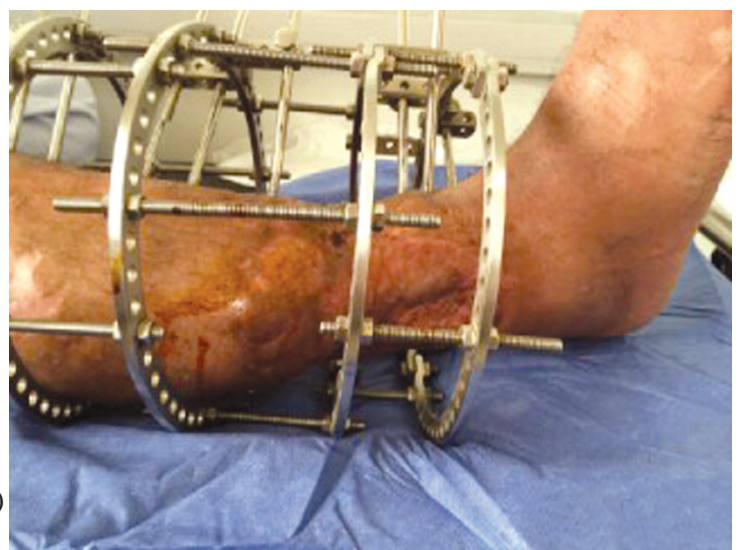

Case (2): Male patients with chronic neglected wound since 2 month. (A) During presentation. (B) After debridement with exposed lower third tibia. (C) After PRP application. (D) After healing with skin graft. 
Table (1): Age, gender and special habits in the studied cases.

\begin{tabular}{|c|c|c|c|c|c|c|}
\hline & \multicolumn{2}{|c|}{$\begin{array}{c}\text { PRP } \\
\text { patients } \\
(\mathrm{n}=10)\end{array}$} & \multicolumn{2}{|c|}{$\begin{array}{l}\text { NPWT } \\
\text { patients } \\
(\mathrm{n}=10)\end{array}$} & \multirow{2}{*}{$\begin{array}{c}\text { Test } \\
\text { of sig. }\end{array}$} & \multirow{2}{*}{$p$} \\
\hline & No. & $\%$ & No. & $\%$ & & \\
\hline $\begin{array}{c}\text { Age (years): } \\
\quad<35 \\
\quad>35\end{array}$ & $\begin{array}{l}7 \\
3\end{array}$ & $\begin{array}{l}70.0 \\
30.0\end{array}$ & $\begin{array}{l}4 \\
6\end{array}$ & $\begin{array}{l}40.0 \\
60.0\end{array}$ & $\begin{array}{l}\chi^{2}= \\
1.818\end{array}$ & $\begin{array}{l}F E_{p=} \\
0.370 \text { (NS) }\end{array}$ \\
\hline $\begin{array}{l}\text { Min. - Max. } \\
\text { Mean } \pm \text { SD. } \\
\text { Median }\end{array}$ & \multicolumn{2}{|c|}{$\begin{array}{l}17.0-55.0 \\
30.6 \pm 11.7\end{array}$} & \multicolumn{2}{|c|}{$\begin{array}{l}16.0-53.0 \\
37.5 \pm 11.9\end{array}$} & $\begin{array}{l}t= \\
1.311\end{array}$ & $\begin{array}{l}0.206 \\
\text { (NS) }\end{array}$ \\
\hline $\begin{array}{l}\text { Gender: } \\
\quad \text { Male } \\
\text { Female }\end{array}$ & $\begin{array}{l}9 \\
1\end{array}$ & $\begin{array}{l}90.0 \\
10.0\end{array}$ & $\begin{array}{l}8 \\
2\end{array}$ & $\begin{array}{l}80.0 \\
20.0\end{array}$ & $\begin{array}{l}\chi^{2}= \\
0.392\end{array}$ & $\begin{array}{l}\mathrm{FE}_{\mathrm{p}}= \\
1.000(\mathrm{NS})\end{array}$ \\
\hline $\begin{array}{l}\text { Special habit } \\
\text { Non } \\
\text { Smoker }\end{array}$ & $\begin{array}{l}7 \\
3\end{array}$ & $\begin{array}{l}70.0 \\
30.0\end{array}$ & $\begin{array}{l}6 \\
4\end{array}$ & $\begin{array}{l}60.0 \\
40.0\end{array}$ & $\begin{array}{l}\chi^{2}= \\
0.220\end{array}$ & $\begin{array}{l}\mathrm{FE}_{\mathrm{p}=} \\
1.000(\mathrm{NS})\end{array}$ \\
\hline
\end{tabular}

Table (2): Clinical data of the wound character.

\begin{tabular}{|c|c|c|c|c|c|c|}
\hline \multirow[t]{2}{*}{$\begin{array}{l}\text { Clinical data of } \\
\text { wound character }\end{array}$} & \multicolumn{2}{|c|}{$\begin{array}{c}\text { PRP } \\
\text { patients } \\
(\mathrm{n}=10)\end{array}$} & \multicolumn{2}{|c|}{$\begin{array}{c}\text { NPWT } \\
\text { patients } \\
(\mathrm{n}=10)\end{array}$} & \multirow[t]{2}{*}{$\begin{array}{l}\text { Test } \\
\text { of sig. }\end{array}$} & \multirow[t]{2}{*}{$p$} \\
\hline & No. & $\%$ & No. & $\%$ & & \\
\hline \multicolumn{7}{|l|}{ Course: } \\
\hline Fluctuating & 3 & 30.0 & 4 & 40.0 & \multirow{4}{*}{$\begin{array}{l}\chi^{2}= \\
1.397\end{array}$} & \multirow{2}{*}{$\begin{array}{l}\mathrm{MC}_{\mathrm{p}}= \\
1.000\end{array}$} \\
\hline Stationary & 5 & 50.0 & 5 & 50.0 & & \\
\hline Progressive & 1 & 10.0 & 0 & 0.0 & & \multirow{2}{*}{ (NS) } \\
\hline Regressive & 1 & 10.0 & 1 & 10.0 & & \\
\hline \multicolumn{7}{|l|}{ Site of wound: } \\
\hline Left leg & 3 & 30.0 & 6 & 60.0 & \multirow{4}{*}{$\begin{array}{l}\chi^{2}= \\
3.793\end{array}$} & \multirow{4}{*}{$\begin{array}{l}\mathrm{MC}_{\mathrm{p}}= \\
0.360 \\
\text { (NS) }\end{array}$} \\
\hline Right leg & 4 & 40.0 & 1 & 10.0 & & \\
\hline Right foot & 3 & 30.0 & 2 & 20.0 & & \\
\hline Lt thigh & 0 & 0.0 & 1 & 10.0 & & \\
\hline \multicolumn{7}{|l|}{ Size of wound: } \\
\hline Min. - Max. & \multirow{2}{*}{\multicolumn{2}{|c|}{$\begin{array}{l}4.0-15.0 \\
11.0 \pm 3.3\end{array}$}} & \multicolumn{2}{|c|}{$10.0-15.0$} & \multirow{3}{*}{$\begin{array}{l}t= \\
1.460\end{array}$} & \multirow{3}{*}{$\begin{array}{l}0.162 \\
\text { (NS) }\end{array}$} \\
\hline Mean \pm SD. & & & 12.7 & 1.64 & & \\
\hline Median & 12.0 & 12.0 & 12.5 & 12.5 & & \\
\hline \multicolumn{7}{|l|}{ Type of wound: } \\
\hline Post Burn & 1 & 10.0 & 2 & 20.0 & \multirow{3}{*}{$\begin{array}{l}\chi^{2}= \\
0.834\end{array}$} & \multirow{3}{*}{$\begin{array}{l}\mathrm{MC}_{\mathrm{p}}= \\
1.000 \\
(\mathrm{NS})\end{array}$} \\
\hline Traumatic & 7 & 70.0 & 7 & 70.0 & & \\
\hline Venous & 2 & 20.0 & 1 & 10.0 & & \\
\hline \multicolumn{7}{|c|}{ Floor of the wound: } \\
\hline Unhealthy & 5 & 50.0 & 4 & 40.0 & $\chi^{2}=$ & $\mathrm{MC}_{\mathrm{p}=}$ \\
\hline Healthy & 5 & 50.0 & 6 & 60.0 & 0.202 & $\begin{array}{l}1.000 \\
\text { (NS) }\end{array}$ \\
\hline \multicolumn{7}{|l|}{ Discharge: } \\
\hline No & 5 & 50.0 & 5 & 50.0 & $\chi^{2}=$ & 1.000 \\
\hline Yes & 5 & 50.0 & 5 & 50.0 & 0.00 & (NS) \\
\hline \multicolumn{7}{|c|}{ Draining lymph node: } \\
\hline Not palpable & 5 & 50.0 & 6 & 60.0 & $\chi^{2}=$ & $\mathrm{FE}_{\mathrm{p}=}$ \\
\hline Palpable & 5 & 50.0 & 4 & 40.0 & 0.202 & $\begin{array}{l}1.000 \\
\text { (NS) }\end{array}$ \\
\hline
\end{tabular}

Table (3): Previous treatment in the studied cases.

\begin{tabular}{|c|c|c|c|c|c|c|}
\hline \multirow[t]{2}{*}{$\begin{array}{l}\text { Previous } \\
\text { treatment }\end{array}$} & \multicolumn{2}{|c|}{$\begin{array}{c}\text { PRP } \\
\text { patients } \\
(\mathrm{n}=10)\end{array}$} & \multicolumn{2}{|c|}{$\begin{array}{l}\text { NPWT } \\
\text { patients } \\
(\mathrm{n}=10)\end{array}$} & \multirow[t]{2}{*}{$\chi^{2}$} & \multirow[t]{2}{*}{$\mathrm{MC}_{\mathrm{p}}$} \\
\hline & No. & $\%$ & No. & $\%$ & & \\
\hline No & 6 & 60.0 & 6 & 60.0 & & \\
\hline Skin Graft & 3 & 30.0 & 4 & 40.0 & 1.147 & $1.000(\mathrm{NS})$ \\
\hline V-Y flap & 1 & 10.0 & 0 & 0.0 & & \\
\hline
\end{tabular}

Table (4): Vascular endothelial grow the factor expression.

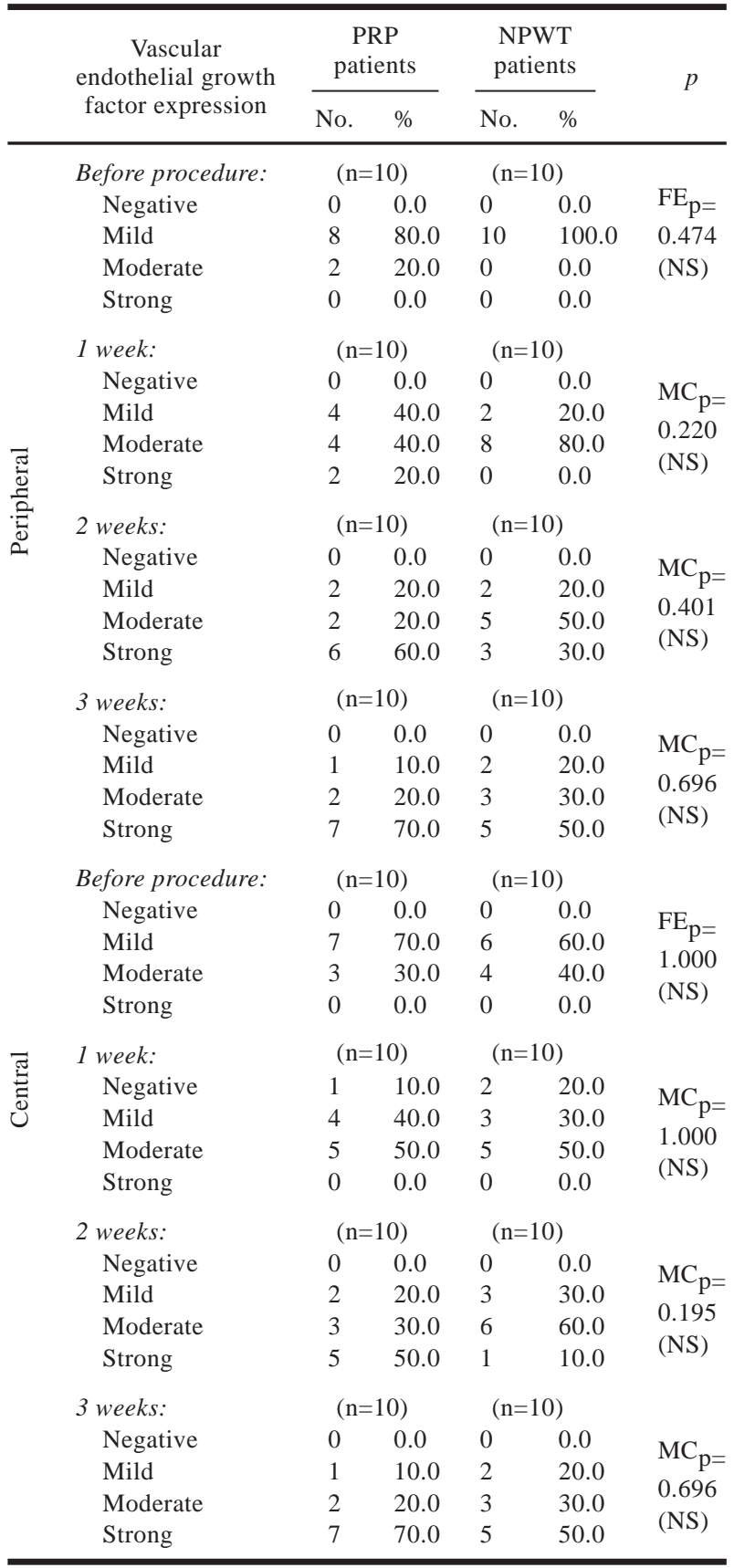

Table (5): Results of wound biopsy.

\begin{tabular}{|c|c|c|c|c|}
\hline $\begin{array}{l}\text { CD31 } \\
\text { (average) }\end{array}$ & $\begin{array}{c}\text { PRP } \\
\text { patients } \\
(\mathrm{n}=10)\end{array}$ & $\begin{array}{c}\text { NPWT } \\
\text { patients } \\
(\mathrm{n}=10)\end{array}$ & $\mathrm{U}$ & $\mathrm{p}$ \\
\hline \multicolumn{5}{|l|}{ Peripheral: } \\
\hline Min. - Max. & $4.50-14.25$ & $4.25-12.25$ & & \\
\hline Mean \pm SD & $9.95 \pm 3.64$ & $8.35 \pm 3.25$ & 38.00 & 0.364 \\
\hline Median & 11.13 & 8.0 & & (NS) \\
\hline \multicolumn{5}{|l|}{ Central: } \\
\hline Min. - Max. & $3.0-12.75$ & $4.75-12.75$ & & \\
\hline Mean \pm SD & $8.58 \pm 3.51$ & $8.38 \pm 3.12$ & 49.50 & 0.970 \\
\hline Median & 9.50 & 8.0 & & (NS) \\
\hline
\end{tabular}


Table (6): Pain scale in the studied cases.

\begin{tabular}{|c|c|c|c|c|c|c|}
\hline \multirow[t]{2}{*}{ Pain Scale } & \multicolumn{2}{|c|}{$\begin{array}{c}\text { PRP } \\
\text { patients } \\
(\mathrm{n}=10)\end{array}$} & \multicolumn{2}{|c|}{$\begin{array}{l}\text { NPWT } \\
\text { patients } \\
(\mathrm{n}=10)\end{array}$} & \multirow[t]{2}{*}{$\begin{array}{c}\text { Test } \\
\text { of sig. }\end{array}$} & \multirow[t]{2}{*}{$p$} \\
\hline & No. & $\%$ & No. & $\%$ & & \\
\hline 2 & 3 & 30.0 & 0 & 0.0 & $\chi^{2}=$ & $\mathrm{MC}_{\mathrm{p}=}$ \\
\hline 3 & 7 & 70.0 & 7 & 70.0 & $5.228 *$ & 0.0 .47 \\
\hline 4 & 0 & 0.0 & 3 & 30.0 & & (Sig.) \\
\hline Min. - Max. & \multicolumn{2}{|c|}{$2.0-3.0$} & \multicolumn{2}{|c|}{$3.0-4.0$} & $\mathrm{U}=$ & 0.017 \\
\hline Mean \pm SD & \multicolumn{2}{|c|}{$2.7 \pm 0.5$} & \multicolumn{2}{|c|}{$3.3 \pm 0.5$} & $24.50 *$ & (Sig.) \\
\hline Median & \multicolumn{2}{|c|}{3.0} & \multicolumn{2}{|c|}{3.0} & & \\
\hline
\end{tabular}

Table (7): Clinical outcome of the study.

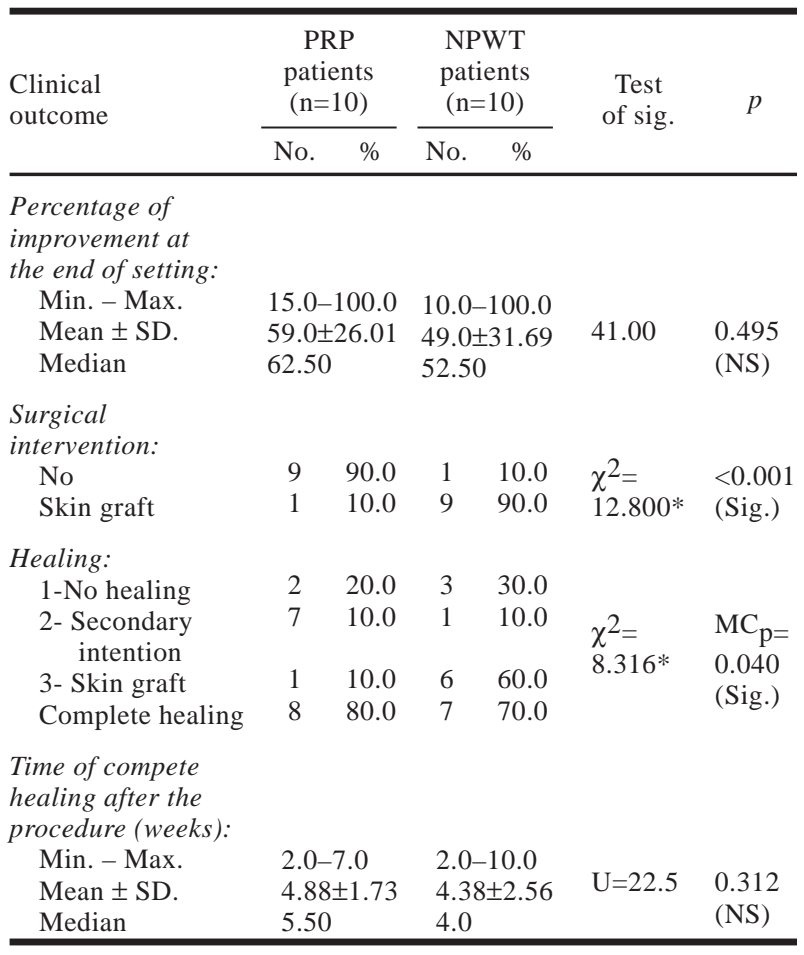

\section{DISCUSSION}

Several studies showed that the platelet growth factors stimulate epithelial formation by the effect of platelet in the process of healing. It stimulates cell division, proliferation, migration, angiogenesis and revascularization, thus promoting chronic wound healing by granulation tissue formation [14].

Negative pressure treatment had been introduced as a component of therapy for patients with chronic wounds. It act by maintaining a moist environment, optimizing blood flow, removing exudates, and applying negative pressure to promote wound closure, these devices are able to initiate numerous factors that may be deficient in a chronic wound. Additionally, numerous studies had shown that these devices are associated with increase rate of granulation tissue formation in these wounds [15].

This study had different characters from previous trials in the type of comparison. In this study the comparison between PRP and NPWT on chronic wound healing. Previous studies mainly focused on each type of applications separately in relation to ordinary dressing.

Early induction of wound healing was due to early high expression of the VEGF Erba et al., [16]. Similarly, in the present study, VEGF were elevated in the NPWT group which had been shown significant elevation after first week of NPWT application in peripheral tissue biopsy but different in central tissue biopsy that had been shown significant elevation after third week of NPWT application. These results strongly suggest that VEGF appear early and are involved in the differentiation and growth of the vascular system. Studies of CD-31 stained wound tissue biopsy and analysis of newly formed vessels demonstrated that NPWT treatment had a regulatory effect on wound angiogenesis. Dini et al., [17] found that there was increase in the number of CD31 posi-tive blood vessels was noted in the NPWT group after treatment (53.83 \pm 16.98 on day 0 and $62.89 \pm 16.98$ on day 7). Similarly in this study there is increase in the number of CD31 posi-tive blood vessels noted in the NPWT group after treatment $(4.10 \pm 0.88$ on day $0,7.0 \pm 1.83$ on day 7 ) in peripheral tissue biopsy. Similarly, in the present study, there was significant elevation of CD-31 in the NPWT group from the first week of application in both peripheral and central wound tissue biopsy. Wilcox et al., [18] found that the median healing rate was $50 \%$ compared with $28 \%$ in centers with less frequent debridement. In this study $60 \%$ of 10 patients of the patients were treated with PRP a had made surgical debridement, $70 \%$ (7 patients) of the patients were treated with NPWT a had made surgical debridement before application of NPWT dressing which improve the Percentage of improvement at the end of setting in PRP patients was $59.0 \pm 26.01 \%$ and in NPWT patients was $49.0 \pm 31.69 \%$. The explanation was removal of necrotic tissue, bacteria, and other foreign bodies from the wound, they supply the key multiple growth factors for healing and debridement transforms the chronic wound to an acute wound and therefore enhance healing. Armstrong \& Lavery [19] found that most wounds healed by secondary intention after application of NPWT $40 \%$ of 77 patients without definitive surgical interference. Only $16 \%$ of the patients had healed wounds after surgical closure in the NPWT group. On the contrary in this study that included $10 \%$ 
(one patient) of the wounds healed by secondary intension and 6 patients (60\%) healed by surgical interference in the form of skin graft. Yao et al., [20] described that despite the greater significant co-morbidities $58.5 \%$ of 171 patients in the form of coronary heart disease, cerebrovascular disease, diabetes, peripheral arterial disease, chronic renal disease and congestive heart disease receiving NPWT treatment healed faster. In this study all these co-morbidities had been excluded as it delayed the healing process. Lalezari et al. (2016) [21] reported that following NPWT, a median of $90 \%$ of the wound bed was granulation tissue creating a much improved surface for graft survival. In this study the patients were treated by NPWT were shown complete healing $70 \%$ (7 patients) by secondary intension $10 \%$ (one patient), skin graft $60 \%$ (6 patients) this explain that NPWT promote granulation tissue formation. Hurd et al., [1] was concluded that $95.9 \%$, Mild - 3\%, Moderate - $1 \%$ no pain, on application of pressure when dressings changed every 2-3 days. In this study we found that pain scale was $70 \%$ mild and $30 \%$ moderate. The difference may be due to each wound is individual with unique characteristics such as size, site, cause, or type of tissue affected.

A study performed by Frykberg et al., [22] found that there were a reduction in area, volume and undermining of the wounds on forty nine patients with sixty five chronic wounds concluded that sixty three patients with chronic wounds gave response with a mean of 2.8 weeks. Kakudo et al., [23] were used autologous PRP in management 5 patients with non healed wounds found that there was complete healing within 4 weeks in 3 wounds with average 6.6 weeks in epithelialization of wounds. Suthar et al., [24] described that there was decrease in size of the wound, and the mean time of wound healing was $8.2 \pm 1.9$ weeks in twenty four patients with one non healed wound in every patient using single dose of a combination of autologous PRP gel and PRP injections subcutaneously in and around the wound periphery. All the patients showed healing of the wound. Danielsen et al., [25] noticed that no difference in the macroscopic epithelialization between control groups and PRP patients in their study. In our study time of compete healing after the procedure the Mean \pm SD $4.88 \pm 1.73$ weeks and the percentage of healing was $80 \%$ of 10 patients in addition, Steenvoorde et al., [26] reported that more than one application was needed in a study of Thirteen wounds in twelve patients, the result was that 7 wounds required PRP application more than one with a mean treatment period of 4.2 weeks this meet with our study that we had applied PRP twice weekly.

In conclusion: PRP and NPWT are a novel tools in management of chronic wounds. PRP is more simple, more safe, less costly, shorter time for the method, less painful, no hospital stay and autologous nature in the preparation had proved the superiority over NPWT.

\section{REFERENCES}

1- Hurd T., Chadwick P., Cote J., Cockwill J., Mole R. and Smith J.M.: Impact of gauze-based NPWT on the patient and nursing experience in the treatment of challenging wounds. International Wound Journal, 7 (6): 448-455, 2010 .

2- Gupta S., Gabriel A., LantisJ. and Téot L.: Clinical recommendations and practical guide for negative pressure wound therapy with instillation. Int. Wound J., 13: 159$174,2016$.

3- Masiero F.S. and Thyssen P.J.: Evaluation of conventional therapeutic methods versus maggot therapy in the evolution of healing of tegumental injuries in Wistar rats with and without diabetes mellitus. Parasitol Res., 115 (6): 24032407, 2016.

4- Guo S.C., Tao S.C., Yin W.J., Qi X., Yuan T. and Zhang C.Q.: Exosomes derived from platelet-rich plasma promote the re-epithelialization of chronic cutaneous wounds via activation of YAP in a diabetic rat model, 7 (1): 81-96, 2017.

5- Ann H., Bart Landuyt, Martin S. Highley, Han Wildiers and Allan T. Van: Vascular Endothelial Growth Factor and Angiogenesis. Pharmacological Reviews, Vol. 56, (4): 549-580, 2004.

6- Johnson K. and Wilgus T.: Vascular Endothelial Growth Factor and Angiogenesis in the Regulation of Cutaneous Wound Repair. Advances in Wound Care, 3 (10): 647 661, 2014.

7- Argenta L.C. and Morykwas M.J.: Vacuum-assisted closure: A new method for wound control and treatment: Clinical experience. Ann. Plast. Surg., 38 (6): 563-576; discussion 577, 1997.

8- Kairinos N., McKune A., Solomons M., Hudson D.A. and Kahn D.: The flaws of laser Doppler in negative-pressure wound therapy research. Wound Repair Regen, 22 (3): 424-429, 2014.

9- Pietrzark W. and Eppley B.: Platelet rich plasma: Biology and new technology. J. Cranio Facial Surg., 16 (6): 10431054, 2005.

10- Andia I. and Abate M.: Platelet-rich plasma: Underlying biology and clinical correlates. Regen Med., 8 (5): 645658,2013

11- Nurden A.: Platelets, inflammation and tissue regeneration. Thromb Haemost, 105 (Supple 1): S13-33, 2011.

12- Kececi Y., Ozsu S. and Bilgir O.: A cost- effective method for obtaining standard platelet-rich plasma. Wound, 26 (8): 232-238, 2014. 
13- Gasbarro R: Negative pressure wound therapy: A clinical review. wounds: Compendium of clinical research and practice, 19 (12): 2-7, 2007.

14- Blanton M.W., Hadad I., Johnstone B.H., Mund J.A., Rogers P.I., Eppley B.L. and March K.L.: Adipose stromal cells and platelet-rich plasma therapies synergistically increase revascularization during wound healing. Plast. Reconstr. Surg., 123 (2 Supple): 56S-64S, 2009.

15- Han G. and Ceilley R.: Chronic Wound Healing: A Review of Current Management and Treatments. Adv. Ther., 112, 2017.

16- Erba P., Ogawa R., Ackermann M., Adini A., Miele L.F., Dastouri P., Helm D., Mentzer S.J., D'Amato R.J., Murphy G.F., Konerding M.A. and Orgill D.P.: Angiogenesis in wounds treated by microdeformational wound therapy. Ann. Surg., 253 (2): 402-409, 2011.

17- Dini V., Miteva M., Romanelli Bertone M. and Romanelli M.: Immunohistochemical evaluation of venous leg ulcers before and after negative pressure wound therapy. Wounds, 23 (9): 257-266, 2011.

18- Wilcox J.R., Carter M.J. and Covington S.: Frequency of debridement and time to heal: A retrospective cohort study of 312-744 wounds. JAMA Dermatol., 149 (9): 1050$1058,2013$.

19- Armstrong D.G. and Lavery L.A.: Diabetic Foot Study Consortium. Negative pressure wound therapy after partial diabetic foot amputation: A multicentrerandomized controlled trial. Lancet, 366 (9498): 1704-1710, 2005.

20- Yao M., Fabbi M., Hayashi H., Park N., Attala K., Gu G., French M.A. and Driver V.R.: A retrospective cohort study evaluating efficacy in high-risk patients with chronic lower extremity ulcers treated with negative pressure wound therapy. Int. Wound J., 11 (5): 483-488, 2014.

21- Lalezari S., Lee C.J., Borovikova A.A., Banyard D.A., Paydar K.Z., Wirth G.A. and Widgerow A.D.: Deconstructing negative pressure wound therapy. Int. Wound J., 2-3, 2016.

22- Frykberg R.G., Driver V.R., Carman D., Lucero B., BorrisHale C., Fylling C.P., Rappl L.M. and Clausen P.A.: Chronic wounds treated with a physiologically relevant concentration of platelet-rich plasma gel: A prospective case series. Ostomy Wound Manage, 56 (6): 36-44, 2010.

23- Kakudo N., Kushida S., Ogura N., Hara T. and Suzuki K.: The use of autologous platelet rich plasma in the treatment of intractable skin ulcer. Open J. Reg. Med., 1 (3): 29-32, 2012.

24- Suthar M., Gupta S., Bukhari S. and Ponemone V.: Treatment of chronic non-healing ulcers using autologous platelet rich plasma: A case series. J. Biomed Sci., 24(1):16-26, 2017.

25- Danielsen P., Jorgensen B., Karlsmark T., Jorgensen L.N. and Agren M.S: Effect of Topical Autologous PlateletRich Fibrin versus No Intervention on Epithelialization of Donor Sites and Meshed Split-Thickness Skin Auto grafts: A Randomized Clinical Trial. Plastic and Reconstructive Surgery, 122 (5): 1431-1440, 2008.

26- Steenvoorde P., van Doorn L.P., Naves C. and Oskam J.: Use of autologous platelet rich fibrin on hard-to-heal wounds. J. Wound Care, 17: 60-63, 2008. 